\title{
Glutathione biosynthesis and metabolism in Plasmodium falciparum
}

\author{
Eva-Maria Patzewitz ${ }^{*}$ Sylke Müller \\ From Parasite to Prevention: Advances in the understanding of malaria \\ Edinburgh, UK. 20-22 October 2010
}

Intraerythrocytic Plasmodium falciparum live in an environment of increased oxidative stress primarily due to their metabolism of host cell haemoglobin. Therefore the parasites depend on functional and effective antioxidant systems. They possesses a glutathione redox system consisting of the tripeptide glutathione (GSH), the enzymes required for glutathione biosynthesis $\gamma$-glutamylcysteine synthetase ( $\gamma \mathrm{GCS}$ ) and glutathione synthetase (GS), as well as a glutathione reductase, glutaredoxins I and II and a single glutathione-S-transferase.

As opposed to the murine malaria species $P$. berghei we show here that $P$. falciparum relies on a functional GSH biosynthesis during blood stage development with $\gamma$ GCS and GS being critical for parasite survival. Our data strongly suggest that there are significant metabolic differences between the human and murine malaria species that must be considered when evaluating and identifying potential drug targets. We further show that the importance for GSH biosynthesis in P. falciparum is attributable to the rapid efflux of glutathione from the infected red cell and the parasite's inability to scavenge sufficient amounts of the tripeptide from its environment to compensate this constant loss of GSH. The essential role for maintaining adequate intracellular GSH levels during blood stage development is further corroborated by the fact that inhibition of $\gamma \mathrm{GCS}$ with the specific inhibitor L-buthionine sulphoximine causes a rapid decrease in cellular glutathione levels in the parasite and has a plasmodicidal effect. Over-expression of $\gamma$ GCS decreases the susceptibility to L-buthionine sulphoximine and results in a decrease in glutathione reductase levels. This presumably leads to an increased efflux of glutathione disulphide resulting in no apparent changes in intracellular GSH levels between wild-type

Research Institute for Infection, Immunity \& Inflammation and Wellcome Centre for Molecular Parasitology, School of Life Sciences, University of Glasgow, Glasgow, UK and $\gamma \mathrm{GCS}$ over-expressing parasites. These data indicate that the parasite's glutathione metabolism is tightly regulated by biosynthesis, reduction and efflux.

Published: 20 October 2010

\section{doi:10.1186/1475-2875-9-S2-P37}

Cite this article as: Patzewitz and Müller: Glutathione biosynthesis and metabolism in Plasmodium falciparum. Malaria Journal 2010 9(Suppl 2): P37.

\section{Submit your next manuscript to BioMed Central and take full advantage of: \\ - Convenient online submission \\ - Thorough peer review \\ - No space constraints or color figure charges \\ - Immediate publication on acceptance \\ - Inclusion in PubMed, CAS, Scopus and Google Scholar \\ - Research which is freely available for redistribution \\ Submit your manuscript at www.biomedcentral.com/submit}

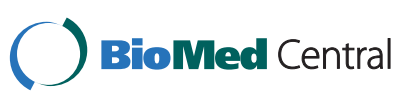

